\title{
Clinical Profile of Febrile convulsion among admitted children in a tertiary care hospital at Dhaka city
}

\author{
R Biswas ${ }^{1}$, A S Munsi ${ }^{2}$, M M Rahman ${ }^{3}$, N Begum ${ }^{4}$, R C Das ${ }^{5}$
}

${ }^{1}$ Dr. Rabi Biswas

Assistant professor

Dept. of Paediatric

Endocrinology \& Metabolic Disorders

Bangladesh Institute of Child Health

\& Dhaka Shishu (Children) Hospital

${ }^{2}$ Dr. Abu Sayed Munsi

Assistant professor

Dept. of Paediatric Cardiology

${ }^{3}$ Dr. Md. Maksudur Rahman

Assistant professor

Dept. of Neonatology

${ }^{4}$ Dr. Nasreen Begum

Assistant Professor

Dept. of Community Medicine

Northern International Medical College

${ }^{5}$ Rajib Chandra Das

Biostatistician

Child Health Research Foundation

Dept. of Microbiology

Dhaka Shishu (Children) Hospital

2, 3

Bangladesh Institute of Child Health \& Dhaka Shishu (Children) Hospital

\section{Correspondence}

Dr. Rabi Biswas

MBBS, DCH, FCPS (Paed), M. Phil (HK)

Assistant Professor

Dept. of Paediatric Endocrinology \&

Metabolic Disorders

Bangladesh Institute of Child Health

\& Dhaka Shishu (Children) Hospital

E-mail: rabibiswasdr@gmail.com

\section{Abstract}

Background : Febrile convulsion (FC) is the most common type of seizure that occurs in children aged $4-60$ months, which is benign and had a good prognosis.

Objective : To evaluate the clinical profile and management of hospitalized children with Febrile convulsion.

Methodology : This cross sectional study was done in Dhaka Shishu (children) Hospital during July 01, 2013 to June 30, 2014. Total 80 children aged between $4-72$ months who were admitted in to Pediatric Medicine department with diagnosis of FC were purposively recruited in the study. Data were collected by a trained physician from history, clinical examination, laboratory findings, treatment and outcome using a structured questionnaire.

Results : Among the study children 41(51.3\%) were between 6 months to 12 months with a male to female ratio was1.5:1. Forty-nine $(61.2 \%)$ children had simple seizures, and $16(20 \%)$ of the patients had family history of febrile seizures. In 70 $(87.5 \%)$ cases the duration of seizure was less than 15 minutes and $75 \%$ patients had less than one attack within 24 hours of onset of fever. Upper respiratory tract infection was the most common (31\%) cause of fever followed by unclassified in 21 $(26 \%)$ cases. Complete blood count revealed leukocytosis in 49\% cases, CRP raised in 30\% cases while CSF study and ultrasonography of brain was normal in 30 cases and 10 cases. We could not perform any investigation to isolate possible causative virus. More than $90 \%$ per cent received intravenous broad-spectrum antibiotics and prophylactic anticonvulsant drugs during early days of hospitalization.

Conclusion : In this study, Upper respiratory Tract infection was found as common cause of febrile convulsion. Duration of seizure was less than 15 minutes and Leukocytosis, raised CRP was identified and nearly all patients received broad-spectrum antibiotics during hospital stay.

Keywords : Febrile convulsion; Seizures; Upper respiratory tract infection; Leukocytosis; CRP

\section{Introduction}

Seizures are the most common pediatric neurological disorders. Four to ten percent of children suffer at least one episode of seizure in the first 16 years of life. In most studies, febrile seizures were reported to be the most common type seen in the pediatric population and account for the majority of seizures seen in children younger than 5 years of age, which accounts for about $1 \%$ of all emergency department visits, and about $2 \%$ of children's hospital emergency department visits. ${ }^{1}$

Although most febrile seizures are brief, do not require any specific treatment or workup, and have benign prognosis, witnessing such seizures is a terrifying experience for most parents. Febrile convulsions occur in young children when there is rapid increase in their body temperature. Febrile Convulsion defined as seizures that are provoked by fever of extracranial infective origin and occur in children aged between six months and five years. ${ }^{2}$ It may, however, occur from four months up to six years of age, ${ }^{3}$ although onset above age 7 years is rare. Evidence suggests having a peak incidence at about 18 months of age, whether the child can be neurologically normal or abnormal. ${ }^{4}$ Febrile convulsion may be simple or complex and also may be generalized or partial.

The prevalence of febrile seizures among different communities is between $2-4 \%$, but was as high as $9 \%$ in Japan and $15 \%$ in Mariana Island. ${ }^{5}$ If a child has had a febrile convulsion; he or she is prone to develop more. About four out of ten children who had febrile convulsion will get them again at some stage, although the risk factors differ greatly from child to child. ${ }^{6} \mathrm{~A}$ child is four times more likely to have a febrile convulsion if either parent was affected in their childhood. Children who have their first febrile convulsion before the age of one year has a $50 \%$ chance of further seizures. ${ }^{7}$ Febrile seizures in children are commonly associated with upper respiratory tract 
infections, which are mainly viral in origin. ${ }^{8}$ As a rapid viral diagnosis is not readily available, it is common practice to prescribe antibiotics empirically, despite the danger of masking bacterial meningitis. Fortunately, most febrile seizures are benign and rarely cause brain damage,

This study aimed to provide clinical profile, laboratory characteristics, treatment and outcome of patients with febrile seizure in our setting and to emphasize early identification of underlying cause of fever, which will enable the physician for appropriate counseling and management while avoiding unnecessary therapeutic interventions.

\section{Materials and Methods}

In this cross sectional study, 80 children aged between 4-72 months who were admitted into Pediatric Medicine department of Dhaka Shishu (children) Hospital at Dhaka city between July 01, 2013 and June 30, 2014 with the diagnosis of FC were evaluated. Patients with a past history of afebrile convulsion, metabolic disorders, known illnesses of central nervous system and neurological deficits were excluded from this study.

Data were collected by a trained physician using a structured questionnaire regarding age, gender, type of convulsion (generalized or focal), duration of convulsion, type of the febrile convulsion (simple or complex), temperature (from the history or document on admission), family history of febrile convulsion, family history of epilepsy, past history of the febrile convulsion, underlying causes of fever, signs and symptoms of meningitis, clinical and laboratory data including treatment and outcome of the child.

Investigations including $\mathrm{CBC}$ and serum electrolytes were performed on all children. Other investigations performed considering the history and clinical profile of the individual child were- blood glucose, serum calcium, blood culture, C-reactive protein (CRP) Arterial blood gas analysis, urine for routine and microscopic examination and culture, CXR, Ultrasonography of brain, EEG and CSF analysis. No test for viral isolation was done in any of our cases. A written informed parental consent was obtained for each patient in this study. Data was analyzed by SPSS version ${ }^{16}$.

\section{Results}

A total of 80 patients were included in the study. Out of 80 cases $9(11.25 \%)$ were below six months of age at onset, 41 (51.25\%) between six and 12 months, 19 (23.75\%) between 13 and 18 months and 11 (13.75\%) were above 18 months (Figure-1). Forty eight patients were male and 32 were female (ratio 1.5:1) as shown in (Figure 2).

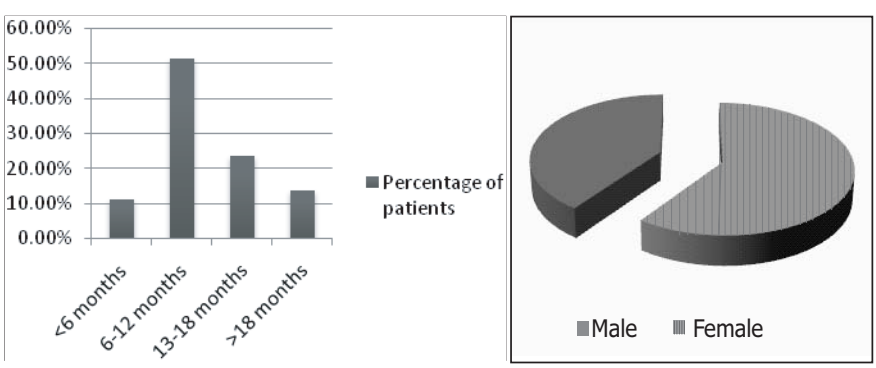

Figure 1 - Age distribution of the Figure 2-Sex distribution study children

Febrile convulsions were generalized in $72(90 \%)$ cases and partial in eight (10\%) cases. In $70(87.5 \%)$ cases the duration of seizure was less than 15 minutes and in rest (12.5\%) it was more than 15 minutes. Attack of convulsion within 24 hours of onset of fever was found in 60 cases (75\%). Family history of febrile convulsion was reported in $16(20 \%)$ cases. Fifty-four patients had the $1^{\text {st }}$ attack of FC this time and recurrent febrile convulsions occurred in 26 (32.5\%) cases, of which 20 had one previous attack and rest six had more than one attack. Type of FC was simple in $49(61.2 \%)$ cases and complex in 31 (38.8\%) cases (Table I).

\begin{tabular}{|c|c|c|}
\hline Type of convulsion & Number & Percentage \\
\hline Generalized & 72 & $90 \%$ \\
\hline Partial & 8 & $10 \%$ \\
\hline \multicolumn{3}{|l|}{ Duration in minutes } \\
\hline$<15$ minutes & 70 & $87.5 \%$ \\
\hline$>15$ minutes & 10 & $12.5 \%$ \\
\hline \multicolumn{3}{|l|}{$\begin{array}{l}\text { Number of attacks } \\
\text { in } 1 \text { st } 24 \text { hours }\end{array}$} \\
\hline One attack & 60 & $75 \%$ \\
\hline >one attack & 20 & $25 \%$ \\
\hline \multicolumn{3}{|l|}{ Family History } \\
\hline Present & 16 & $20 \%$ \\
\hline Absent & 64 & $80 \%$ \\
\hline \multicolumn{3}{|l|}{ Recurrence } \\
\hline $1^{\text {st }}$ attack & 54 & $67.5 \%$ \\
\hline One previous attack & 20 & $25 \%$ \\
\hline$>$ One previous attacks & 6 & $7.5 \%$ \\
\hline \multicolumn{3}{|l|}{ Nature } \\
\hline Simple & 49 & $61.3 \%$ \\
\hline Complex & 31 & $38.7 \%$ \\
\hline \multicolumn{3}{|l|}{ Post-ictal condition } \\
\hline Asleep & 40 & $50 \%$ \\
\hline Awake & 38 & $47.5 \%$ \\
\hline Undetermined & 2 & $2.5 \%$ \\
\hline Post-ictal paralysis & 0 & $0 \%$ \\
\hline
\end{tabular}

From history temperature at the time of convulsion was very high in 60 (75\%) cases and high in rest of the cases. None was afebrile. Duration of fever prior to first convulsion ranged from 0-68 hours and the mean was 16.5 hours. After the first seizure none of the children had any post-ictal paralysis, $40(50 \%)$ out of 80 were asleep and 38 (47.5\%) were awake. Two of the parents were uncertain of their child's condition post-ictally. Over $60 \%$ parents failed to identify fever at the right time and to 
introduce antipyretics effectively before the convulsion took place. The most common symptoms accompanied by the febrile seizure were cough $31(38.8 \%)$ and coryza $25(31.2 \%)$. The other symptoms were diarrhea $10(12.5 \%)$, abdominal pain 5 $(6.2 \%)$, sore throat $7(8.8 \%)$ and dysuria $2(2.5 \%)$ (Table-II).

Table-II. Presenting symptoms other than convulsion and fever on admission

$\begin{array}{lcc}\text { Symptoms } & \text { Number } & \text { (\%) } \\ \text { Cough } & 31 & 38.8 \\ \text { Coryza } & 25 & 31.2 \\ \text { ILoose motion } & 10 & 12.5 \\ \text { Sore throat } & 7 & 8.8 \\ \text { Abdominal pain } & 5 & 6.2 \\ \text { Dysuria } & 2 & 2.5\end{array}$

CBC showed abnormalities suggestive of an infection in $45 \%$, however, only 2 had a positive blood culture. CRP was raised in 24 cases. Anemia and metabolic acidosis were found in 28 and 14 cases respectively (Table-III). None of the patients had gross electrolyte abnormality.

$\begin{array}{lcc}\begin{array}{l}\text { Table - III. Abnormal results on blood examination in Patients with FC } \\ \text { Laboratory findings }\end{array} & \begin{array}{c}\text { Number } \\ \text { Percentage }\end{array} \\ \text { Leukocytosis } & 39 & 48.8 \% \\ \text { Leukopenia } & 3 & 3.7 \% \\ \text { Thrombocytosis } & 4 & 5.0 \% \\ \text { Thrombocytopenia } & 10 & 12.5 \% \\ \text { Anemia } & 28 & 35 \% \\ \text { Metabolic acidosis } & 14 & 17.5 \% \\ \text { CRP (raised) } & 24 & 30 \%\end{array}$

CSF analysis was done in 30 patients no one had abnormal findings in cerebrospinal fluid analysis in favor of meningitis. Chest X-ray was done with suspected LRT cases, of which 11 showed findings suggestive of pneumonia. Ultrasonography of brain was performed on 15 patients (18.7\%), however, these tests did not show any abnormality in any of the cases. EEG was done in only 10 selective cases with complex FC and all EEG reports were normal.

Upper Respiratory Tract Infection (URTI) was the most common cause of febrile illness in our study, although the underlying cause was not determined (Table-IV). A vast majority of cases were unclassified regarding finding of etiology of fever.

Table - IV. Etiology of Fever in Patient with FC

\section{Etiology of Fever}

Upper Respiratory Tract Infection

Pneumonia

Gastroenteritis

Septicaemia

Otitis media

Urinary tract infection

Unclassified

Total
Duration of hospital stay ranged from 3 days to 12 days, median stay was 5 days. Most of the patients $55(69 \%)$ stayed 3-5 days, $20(25 \%)$ 6-8 days and 5(6\%) patients for 9-12 days. All patients were recovered and discharged with advice (Figure-3).

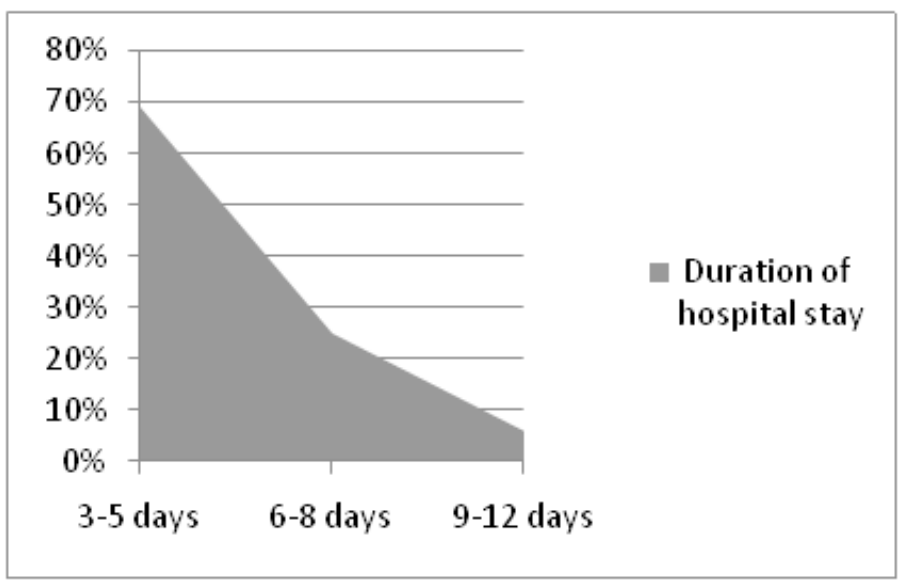

Figure 3 - Duration of hospital stay

Regarding the management, 5(6.2\%) received intravenous fluids (IVF) in the emergency room (ER) and total 73 (91.3\%) during the hospitalization. Patients who were ill-looking received IV fluid in the ER and due to fear of further convulsion patients followed by chance of aspiration were kept nothing per oral and IV fluid was given mainly for providing nutrition. Only2 (2.5\%) children received IV antibiotics in the ER, however, over $92.5 \%$ of the patients received them during hospitalization at least for the initial days. Similarly, over $92.5 \%$ patients received prophylactic anticonvulsant (Table V), mostly Tab. Diazepam at the initial days of hospitalization. Ten patients were given perrectal diazepam and 2 patients required intravenous phenobarbiton at emergency room and after controlling convulsion they were admitted for further management.

\section{Table V- Management of study children}

$\begin{array}{lcc}\text { Received intravenous fluid } & \text { Number } & \text { Percentage } \\ \text { Yes } & 73 & 91.3 \% \\ \text { No } & 7 & 8.7 \% \\ \text { Received intravenous antibiotics } & & \\ \text { Yes } & 74 & 92.5 \% \\ \text { No } & 6 & 7.5 \% \\ \text { Received prophylactic anticonvulsant } & & \\ \text { Yes } & 74 & 92.5 \% \\ \text { No } & 6 & 7.5 \% \\ \text { Discussion } & & \end{array}$

In this study, the majority of children were under 2 years old and our findings were similar to other studies in which FC was in the age range of 6 months to 3 years with peak incidence at the age of 18 months. ${ }^{10 / 9}$ Prevalence of FC was predominant in 
males than females and this is in agreement with the results of other studies. ${ }^{10}$ Here16 patients $(20 \%)$ had a positive family history of FC, while this percentage in the other studies varied widely from $25 \%$ to $40 \%,{ }^{11}$ Ninety percent of children in the present study had generalized convulsion that is similar to findings of Hoque $M$ et al. In our study, 49 children (61.2\%) were suffering from simple $\mathrm{FC}$, while this was between $60 \%$ to $90 \%$ in other study. ${ }^{10}$ Distribution of simple and complex FC varied widely in different studies, ${ }^{12}$ which may be due to difference in criteria adopted.

Duration of seizure of less than 15 minutes was noted in $87.5 \%$ patients in this study, which was close to Bessissco et al findings. ${ }^{13}$

Mean duration of fever prior to first convulsion in our study was 16.5 hours and it was associated with very high fever in majority of the cases, which is consistent with the findings of Deng CT et al. None of patients had any post-ictal paralysis and majority of patients were either asleep or awake. These data were similar to other study. The most common symptoms accompanying the febrile seizure were cough and coryza in our children, which were well correlated to with the findings of Deng CT et al. ${ }^{14}$ but Aliabad et al. ${ }^{15}$ found that loose motion was the most common symptom of febrile illness in his study. URTI was the most common cause of febrile illness in our study, although the underlying pathogen was not determined. A vast majority of cases were unclassified regarding finding of etiology of fever. This is mostly due to lack of facilities to identify the viral origin responsible for the high fever leading to $\mathrm{FC}$ to the predisposed group of children. Otitis media was diagnosed in 5 cases and otitis media remains the most common cause of FC in a study conducted in Carolina. ${ }^{16}$

Investigations reports of $L P$, ultrasonography of brain and EEG were all normal in our patients, which correlates with Aliabad et al. ${ }^{15}$ study and this may be due to very strict inclusion criteria of our study population. However, investigations like neuro imaging are discouraged in simple febrile seizure. Duration of hospital stay depends on the underlying etiology identified and higher number abnormal CBC count (45\%), it was similar to Deng CT et al. ${ }^{14}$ study. More than $90 \%$ received intravenous antibiotics during hospitalization, which should be discouraged, although probably it was given to treat bacterial meningitis or septicaemia due to failure of identifying the responsible virus in our facilities. The same thing is happening in case of use of anti-epileptic drugs (AEDs) like diazepam or phenobarbitone due to prevent further convulsion, although only $25 \%$ cases had a second attack of convulsion in this study. Studies revealed that treatment with antiepileptic drugs does not abort the cluster in most children. ${ }^{17} \mathrm{~A}$ retrospective study reported that diazepam was effective against prevention of second convulsion in only 2 of 16 patients (13\%). ${ }^{18}$ AEDs should be used judiciously in the Emergency room and during hospitalization, which is consistent with the latest American Academy of Pediatrics recommendations that AEDs should not be used routinely to prevent febrile seizure recurrence. ${ }^{19}$

\section{Conclusion}

In this study, Upper respiratory Tract infection was found as common cause of febrile convulsion. Duration of seizure was less than 15 minutes and Leukocytosis, raised CRP was identified and all patients received broad-spectrum antibiotics during hospital stay.

\section{References}

1. Martindale JL, Goldstein JN, Pallin DJ: Emergency department seizure epidemiology. Emerg Med Clin North Am 2011 Feb, 29(1):15-27

2. Ducan JS, Shorvon SD, Fish DR (editors). Clinical Epilepsy, First edition. New Delhi: B.I. Churchil Livingstone Pvt. Ltd, 1995. Pp.74-76.

3. Khan MR. Febrile seizure. Bangladesh Private Medical Practitioners Journal 2003;9:30-31.

4. Shinnar S, \&Glauser TA. Febrile Seizures. J Child Neurol 2002;17:S44.

5. Tsuboi T. Epidemiology of febrile convulsions in children in Japan. Neurology 1984;34:175-181.

6. Wallace SJ. Recurrence of febrile convulsions. Arch Dis Child 1974;49:763-775.

7. Collins T. Febrile convulsion. Institute of Child Health. Great Ormond Street Hospital for Children. Published in The Times of London, 14 March 2000.pp 89-94.

8. Millichap JG, Millichap JJ. Role of viral infec- tions in the etiology of febrile seizures. PediatrNeurol 2006; 35:165-72.

9. Fetveit A. Assessment of febrile seizures in children. Eur J Pediatr. 2008;167(1):17-27.

10. Hoque M, Ali CMH, Zaman MS, Ahmed ASMNU, Hossain MM, Begum JA, Jahan A. Risk Factors For Recurrent Febrile convulsion. Journal of Bangladesh College of Physicians and Surgeons.2004;22(2):49-52.

11. Verity CM, Butler NR, Golding J. Febrile convulsions in a national cohort followed up from birth- Prevalence and recurrence in the first five years of life. Br Med J (Clin Res).1985;290(6478):1307-10.

12. Fallah $\mathrm{R}$, Golestan $\mathrm{M}$. Role of laboratory diagnostic tests in first febrile seizure. J Pediatr Neurol. 2008;6(2):129-132.

13. Bessissco MS, Elsaid MF, Almula NA et al. Recurrence risk after a first febrile convulsion. Saudi Medical Journal 2001;22(3):254-258.

14. Deng CT, Zulkifli HI, Azizi BHO. Febrile seizure in Malaysian Children: Epidemiology and Clinical Features. Med J Malayasia 1994;49:341-347.

15. Aliabad GM, Khajeh A, Fayyazi A, Safdari L. Clinical, Epidemiological and Laboratory Characteristics of Patients with Febrile Convulsion. J ComprPed. 2013;4(3):134-7.

16. Millichap JJ. Febrile seizure management in hospital practice compared to guidelines- In: Program and abstracts of the American Academy of Neurology 60th Annual Meeting (Chicago). Saint Paul, MN: American Academy of Neurology, 2008:A131.p.12-15.

17. Uemura N, Okumura A, Negoro T, et al. Clinical features of benign convulsions with mild gastroenteritis. Brain Dev 2002;24:745-749.

18. Enoki H, Yokota T, Nagasaki R. Single-dose chloral hydrate for benign convulsions with mild gastroenteritis. Epilepsia 2007;48:1026-1028.

19. Bidabadi $E$, Mashouf M. Association between iron deficiency anemia and first febrile convulsion: A case-control study. Seizure. 2009;18(5):347-51. 